\title{
Enhanced Specific Capacitance of Self-assembled Three-dimensional CNT/Layered Silicate/Polyaniline Hybrid Sandwiched Nanocomposite for Supercapacitor Application
}

\author{
R.Oraon ${ }^{\mathrm{a}}$, A. De Adhikari ${ }^{\mathrm{a}}$, S.K.Tiwari ${ }^{\mathrm{a}}$ and G.C.Nayak ${ }^{\mathrm{a} *}$ \\ ${ }^{a}$ Department of Applied Chemistry, ISM Dhanbad, Dhanbad 826004, Jharkhand, India \\ *Corresponding Author Email: nayak.g.ac@ismdhanbad.ac.in
}

Number of Pages: 7

Number of Figures: 5 


\section{Supporting Information}

\section{Experimental section:}

\subsection{Electrode Preparation for electrochemical Analysis:}

A supercapacitor test cell was fabricated with two electrodes prepared by mixing different samples with PVDF and carbon black in the mass ratio of 80:15:5 in dispersant N-methylpyrrolidone and then coated over two symmetrical platinum foils. The prepared samples were vacuum dried overnight at $80^{\circ} \mathrm{C}$ and weight of sample were measured. The electrode are separated by a thin filter paper in $1 \mathrm{M} \mathrm{TEABF}_{4}$ (tetraethyl ammonium tetrafluro borate) in acetonitrile solution. The electrochemical properties and capacitance measurements of supercapacitor electrodes were studied in a two-electrode system by cyclic voltammetry.

\subsection{Cyclic Voltammetry Study in organic electrolyte:}

Electrochemical measurements of nanoclay based composites were done by cyclic voltammetry within two potential region $(0-0.8 \mathrm{~V})$ and $(0-1.6 \mathrm{~V})$ and presented in figure $\mathrm{S} 1$ (a \& b). As can be seen, at $10 \mathrm{mV} / \mathrm{s}$ all $\mathrm{CV}$ curves exhibits deviation from ideal capacitive behavior even at high operating voltage up to $1.6 \mathrm{~V}$ indicating a typical hybrid nanocomposite with both EDLCs and pseudocapacitance. Results revealed that within both potential region $(0-0.8 \mathrm{~V} \& 0$ 1.6V) nanoclay based nanocomposite (ex-situ CAN \&in-situ CNA) possessed maximum current density as compared to other related systems (PANI, NA, CA). Additionally, cyclic enclosed area under cyclic voltammogram of CAN \& CNA is relatively higher than other systems which demonstrates their high degree of capacitive performance. To evaluate the electrode performance, specific capacitance (SC), energy density (ED) and power density (PD) were calculated using the following formulae:

$$
\mathrm{SC}=\left(4 \int_{V-}^{V+} I(V) d v\right) / \mathrm{m} \Delta \mathrm{Vv}
$$

Where, $\mathrm{m}=$ total mass of the active material, $\mathrm{v}=$ scan rate, $\Delta \mathrm{V}=$ voltage window

$$
\mathrm{ED}=1 / 2 \mathrm{CV}^{2}
$$


Where, $\mathrm{C}=$ specific capacitance in $\mathrm{F} / \mathrm{g}, \mathrm{V}=$ Potential window

$$
\mathrm{PD}=\mathrm{E} / \mathrm{t}
$$

Where, $\mathrm{E}=$ Energy Density in $\mathrm{Wh} / \mathrm{Kg}$, $\mathrm{t}=$ time in second

From figure $\mathrm{S} 1$ (c), at scan rate $10 \mathrm{mV} / \mathrm{s}$, maximum specific capacitance value was obtained for CNA (189 F/g) which is relatively higher than CAN (127 F/g), CA (63 F/g). Similar reason could be ascribed to the enhanced specific capacitance of CAN as discussed for aq. 1M $\mathrm{KCl}$ solution. Similar behavior was also observed for NA $(52 \mathrm{~F} / \mathrm{g})$ with increased current density as compared to PANI (22 F/g) at the same scan rate of $10 \mathrm{mV} / \mathrm{s}$. Similar trend was also documented with energy density and power density for in-situ CNA with maximum value of $16.8 \mathrm{Wh} / \mathrm{Kg} \& 378 \mathrm{~W} / \mathrm{Kg}$, respectively at same scan rate. These values are however lower as compared to reported specific capacitance in aqeuous $1 \mathrm{M} \mathrm{KCl}$ solution. The lower value of specific capacitance in organic electrolyte $(1 \mathrm{M}$ TEABF4) may be due to obstruction in ionic mobility during electrochemical analysis due to larger ionic size of electrolyte. In other related work, similar decrease in specific capacitance were evidenced while using organic electrolyte [12]. To resolve such issue of lower specific capacitance, $\mathrm{CV}$ analysis was further performed with extended potential window upto 0-1.6V. Figure S1(b) represents the voltammetric response of as prepared nanoclay based composite. Similar potentiodynamic response were also observed for CNA \& CAN with highest current density as compared to other systems (CA, NA, PANI). It was found that with the increase in potential window upto $1.6 \mathrm{~V}$ all cyclic voltammograms are stable with significantly enhanced current density than in $0-0.8 \mathrm{~V}$. Calculation revealed that specific capacitance of PANI and NA was increased (from $22.38 \mathrm{~F} / \mathrm{g} \& 52 \mathrm{~F} / \mathrm{g}$ to $41.60 \mathrm{~F} / \mathrm{g} \& 120 \mathrm{~F} / \mathrm{g}$, respectively). Similarly, the value of $\mathrm{CA}$ was increased from $63 \mathrm{~F} / \mathrm{g}$ to $133 \mathrm{~F} / \mathrm{g}$ at $10 \mathrm{mV} / \mathrm{s}$. Among nanoclay based nanocomposite, in-situ CNA possessed maximum specific capacitance (275 F/g increased from $189 \mathrm{~F} / \mathrm{g}$ ) than CAN (140.63 F/g increased from $127 \mathrm{~F} / \mathrm{g}$ ). Meanwhile, CNA holds the maximum energy density $(97.94 \mathrm{Wh} / \mathrm{Kg})$ and power density $(1101.82 \mathrm{~W} / \mathrm{Kg})$ at $10 \mathrm{mV} / \mathrm{s}$ which is comparatively higher than other related systems. 


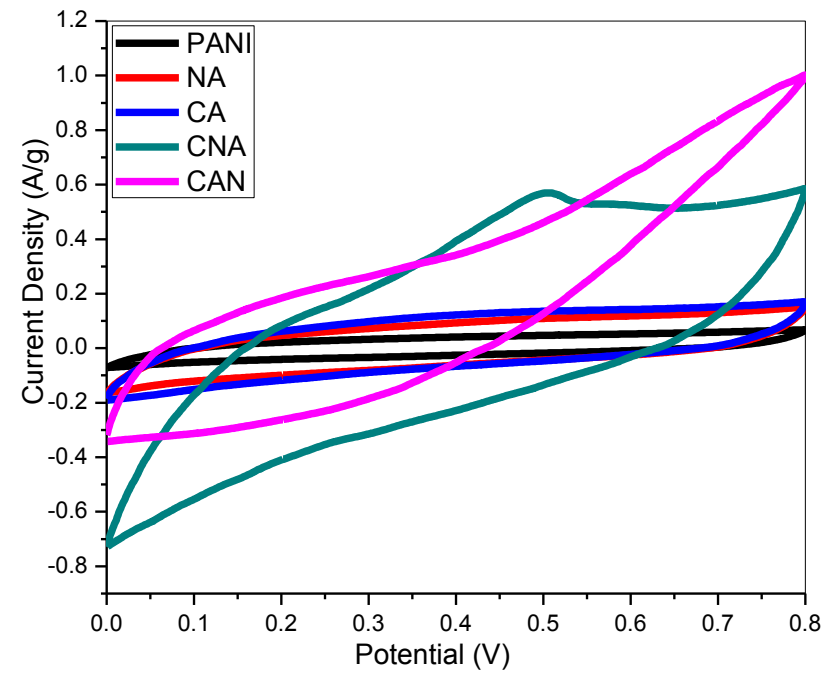

Figure S1 (a): Comparative plots of cyclic voltammetry of different sample at $10 \mathrm{mV} / \mathrm{s}$ in the potential window of $0-0.8 \mathrm{~V}$ in organic electrolyte $\left(\mathrm{TEABF}_{4}\right)$

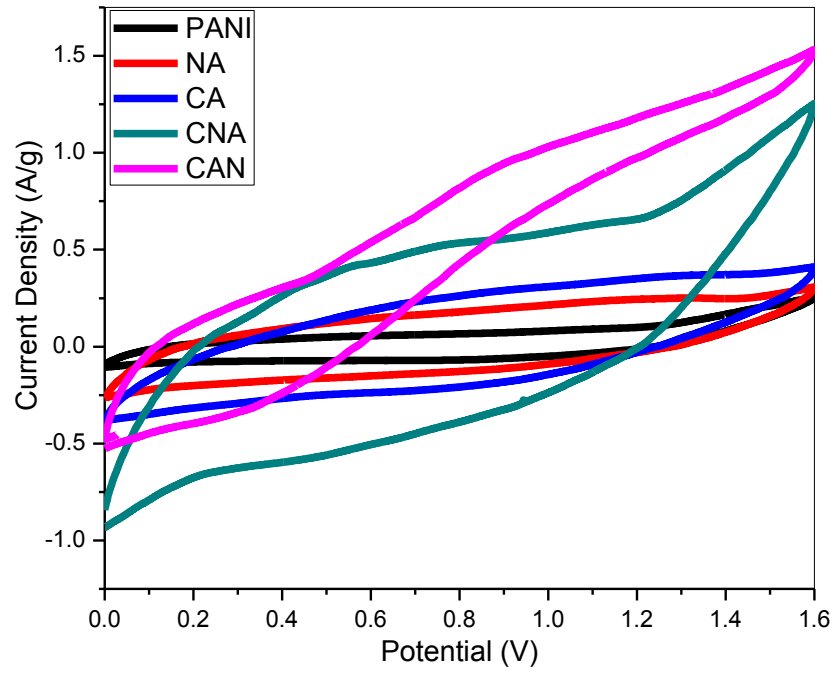

Figure S1(b): Comparative plots of cyclic voltammetry of different sample at $10 \mathrm{mV} / \mathrm{s}$ in the potential window of $0-1.6 \mathrm{~V}$ in organic electrolyte $\left(\mathrm{TEABF}_{4}\right)$ 


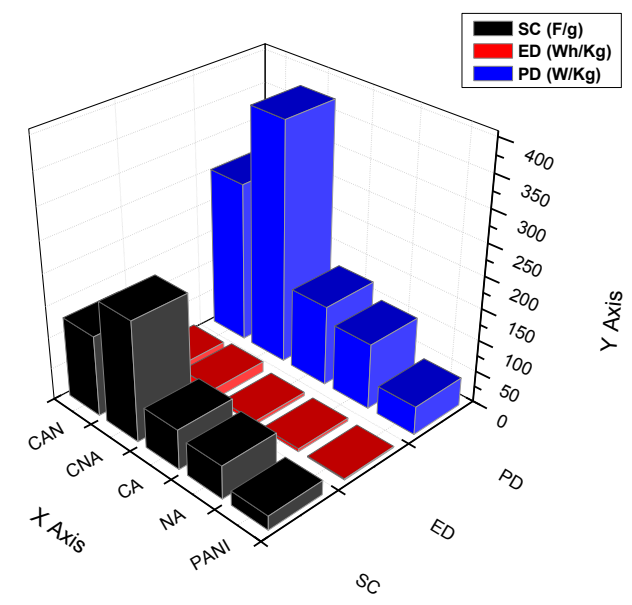

Figure S1(c): Bar plots of SC, ED \& PD of electrode material within potential window (0-0.8 V) in organic electrolyte $\left(\mathrm{TEABF}_{4}\right)$

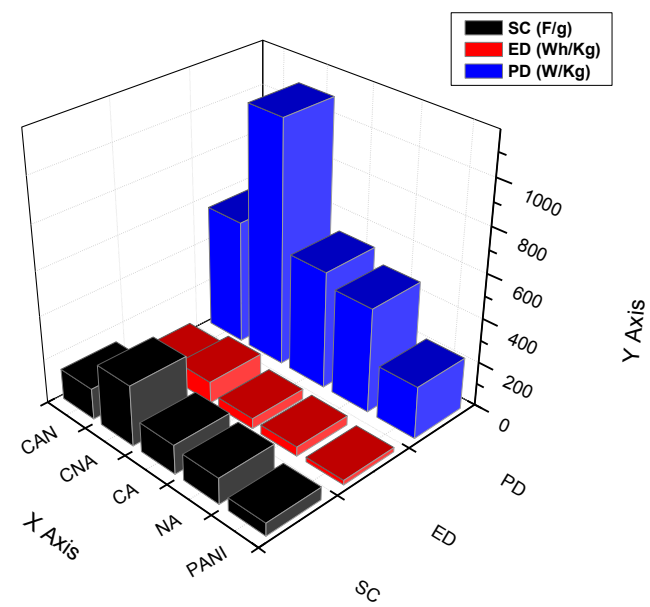

Figure S1(d): Bar plots of SC, ED \& PD of electrode material within potential window (0-1.6 V) in organic electrolyte $\left(\mathrm{TEABF}_{4}\right)$

\section{References:}

1. Liang, Y.; Liang, F.; Zhong, H.; Li, Z.; Fu, R.; Wu, D. An advanced carbonaceous porous network for high-performance organic electrolyte supercapacitor. J. Mater. Chem. A, 2013, 1, 7000-7005

2. Sun, Y.; Wu, Q.; Shi, G. Supercapacitor based on self-assembled graphene organogel. Phys. Chem. Chem. Phys., 2011, 13, 17249-17254 


\subsection{Galvanostatic charging-discharging Analysis}

To further complement the $\mathrm{CV}$ calculations, specific capacitance, and energy density and power density were calculated from charging-discharging curves using the following equations (in aqueous electrolyte):

$$
\text { Specific capacitance }=\mathrm{I} \Delta \mathrm{t} / \mathrm{m} \Delta \mathrm{V}^{1}
$$

Where, $\mathrm{I}=$ applied current $(\mathrm{A}), \mathrm{t}=$ discharging time $(\mathrm{sec}), \mathrm{m}=$ total mass of the electrode $(\mathrm{g}), \Delta \mathrm{V}=$ potential window $(\mathrm{V})$

$$
\text { Energy Density }=1 / 2 C \Delta V^{21}
$$

Where, $\mathrm{C}=$ specific capacitance $(\mathrm{F} / \mathrm{g}), \Delta \mathrm{V}=$ Potential window $(\mathrm{V})$

$$
\text { Power Density }=E / \Delta \mathrm{t}^{1}
$$

Where, $\mathrm{E}=$ Energy density $(\mathrm{Wh} / \mathrm{Kg}), \Delta \mathrm{t}=$ Discharging time $(\mathrm{sec})$

The maximum specific capacitance $(312 \mathrm{~F} / \mathrm{g}$ ) was achieved for in-situ CNA which is relatively higher than ex-situ CAN $(237 \mathrm{~F} / \mathrm{g})$ and CA $(156 \mathrm{~F} / \mathrm{g})$ at a current density of $5 \mathrm{~A} / \mathrm{g}$. The specific capacitance calculated for pure PANI \& NA are $35 \mathrm{~F} / \mathrm{g}$ and $38 \mathrm{~F} / \mathrm{g}$, respectively which suggests the improved electrochemical performance of PANI with nanoclay in nanocomposite (NA). Similar trend was also observed for energy density and power density. The maximum energy density $(27 \mathrm{Wh} / \mathrm{Kg})$ and power density $(1944 \mathrm{~W} / \mathrm{Kg})$ was obtained for in-situ CNA. These results are well consistent with $\mathrm{CV}$ measurements and similar reasons could be ascribed to enhanced performance of as synthesized nanoclay based composites.

\section{Reference}

1. Shen, J.; Yang, C.; Li, X.; Wang, G. High Performance Asymmetric Supercapacitor Based on Nanoarchitectured Polyaniline/Graphene/Carbon Nanotubes and Activated Graphene Electrodes. ACS App. Mater. Interfaces. 2013, 5, 2241-2248

\subsection{Electrochemical impedance spectroscopy:}

EIS study revealed that all EIS spectra composed of common feature of rotated and flattened semicircle arc in the high frequency region followed by straight line in the low 
frequency region. The initial semicircle arc at high frequency region is attributed to charge transfer resistance while straight line indicates capacitive behavior at low frequency. In figure S2 in-situ CNA exhibits lesser solution resistance $\left(\mathrm{R}_{\mathrm{S}}\right)$ than ex-situ CAN with fewer obstruction in charge transfer in high frequency region followed by a straight line in low frequency region. Among all, CA exhibits least solution resistance $\left(\mathrm{R}_{\mathrm{S}}\right)$ as compared to CAN and CNA which may be due to highly conducting nature of CNT array than nanoclay which acts as a transferring media for the charge propagation through bulk of electrode material during electrochemical analysis.

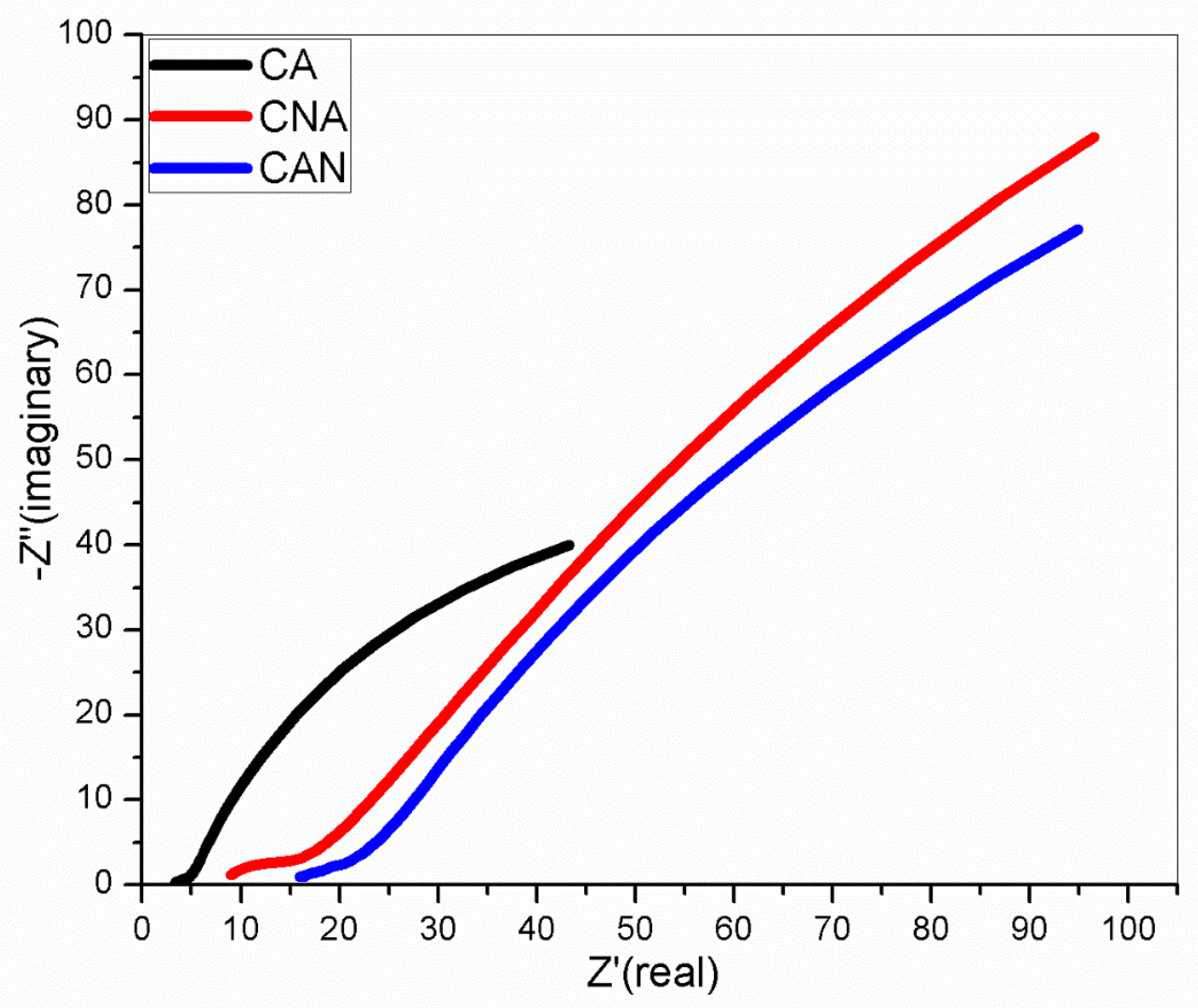

Figure S2: Nyquist plot of CA, CAN and CAN in organic electrolyte $\left(\mathrm{TEABF}_{4}\right)$ 